\title{
Research Article \\ Effect of Hafnium Coating on Osseointegration of Titanium Implants: A Split Mouth Animal Study
}

\author{
Vaishnavi Rajaraman, ${ }^{1}$ Deepak Nallaswamy, ${ }^{1}$ Dhanraj Ganapathy, ${ }^{1}$ S. Rajeshkumar (D), \\ Padma Ariga, ${ }^{1}$ and Karthik Ganesh ${ }^{3}$ \\ ${ }^{1}$ Department of Prosthodontics and Implantology, Saveetha Dental College and Hospital, Saveetha Institute of Medical and \\ Technical Sciences, Chennai 600077, India \\ ${ }^{2}$ Nanobiomedicine Lab, Department of Pharmacology, Saveetha Dental College and Hospital, Saveetha Institute of Medical and \\ Technical Sciences, Chennai 600077, India \\ ${ }^{3}$ Department of Anatomy, BRULAC, Saveetha Dental College and Hospital, Saveetha Institute of Medical and Technical Sciences, \\ Chennai 600077, India
}

Correspondence should be addressed to S. Rajeshkumar; ssrajeshkumar@hotmail.com

Received 1 July 2021; Accepted 1 November 2021; Published 15 December 2021

Academic Editor: Domenico Acierno

Copyright (C) 2021 Vaishnavi Rajaraman et al. This is an open access article distributed under the Creative Commons Attribution License, which permits unrestricted use, distribution, and reproduction in any medium, provided the original work is properly cited.

\begin{abstract}
The behaviour of hafnium as surface coating in biological environments has not been studied. Little is known about osseointegration of hafnium-coated titanium implants. Thus, further studies of hafnium coating under biological conditions are required in order to determine the suitability of this material, as a surface coating for biomedical application. The aim of the study is to analyse the difference between hafnium-coated titanium and uncoated titanium by evaluating the osseointegration ability of hafnium metal and mechanism of which promotes better bone integration. The study was conducted with a split mouth design on 16 Wistar Albino rats of both sexes, at the age of 6-7 months, weighing $2526.5 \pm 74.4 \mathrm{~g}$. Self-tapping titanium osteosynthesis screws $\left(4 \mathrm{~mm} \times 2 \mathrm{~mm}\right.$ ) (LeForte System Bone Screw ${ }^{\circledR}$ ) were implanted in the mandible of rats: Group A (pure titanium screws, $n=12$ ) and Group B (hafnium-coated screws, $n=12$ ). The implanted screws' stability was checked and noted with a specially customised torque apparatus during insertion and removal of implant. The tissue sections were then processed for hematoxylin and eosin and Masson's trichrome for bone and connective tissue examination, after 4 and 8 weeks of placement. Hafnium coating appears to have offered similar biocompatibility (aspartate transaminase (AST), alanine aminotransferase (ALT), and creatine kinase (CK) enzyme assay), statistically significant improvement (independent Student's $t$-test, $p<0.05)$ in insertion torque $(25.42 \pm 3.965)$ and removal torque $(29.17 \pm 2.887)$ than commercially pure titanium with insertion torque $(22.08 \pm .575)$ and removal torque $(25.42 \pm 2.575)$. Hafnium coating in the rat mandible showed promising osseointegration with good tissue biocompatibility. Further human trials of hafnium-coated implants are needed to understand the biological behaviour better to enhance clinical performance.
\end{abstract}

\section{Introduction}

Tissue engineering is a novel and well-proven approach for repair and reconstruction of bone defects. An ideal implant material should have properties that include biocompatibility, corrosion resistance, elastic modulus, and favour bone anchorage [1-14]. One of the most commonly used materials for this purpose is titanium and its alloys. In various studies conducted till date, tantalum has revealed superior properties fulfilling criteria required for an implant which include excellent chemical stability, body fluid resistance, biological inertia, and remarkable osteoconductivity. Although tantalum is shown to be promising in bone defect repair, its elastic modulus is much higher than that of human bone tissue and prone to stress shielding effect [15-25].

We wanted to evaluate alternative elements that may have the potential to offer equivalent or superior osseointegration. One such element of interest is hafnium. In the 


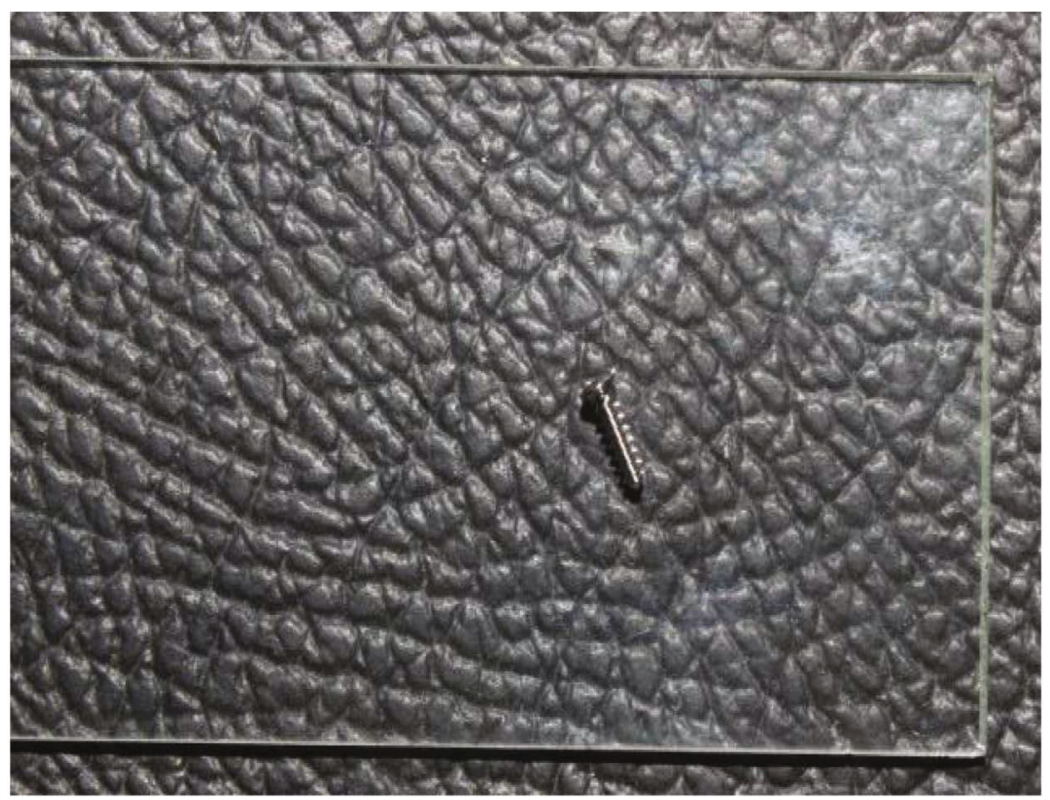

FIGURE 1: Photograph showing commercially pure self-tapping micro titanium osteosynthesis implant screws $(4 \mathrm{~mm} \times 2 \mathrm{~mm})$.

periodic table by IUPAC, tantalum belongs to period $6(\mathrm{~d}$ block) of the periodic table. Hafnium belongs to the same period and block as tantalum, in the periodic table [26-32].

Hafnium is always found in association with zirconium in mineral ores with zircon Hf/Zr of about $2.5 \%$. In 1984 , Marcel Pourbaix proposed hafnium as a metal to be considered for surgical implants due to the passive state of the metal with properties like high ductility, strength, resistance to corrosion, and mechanical damage. Various in vitro studies were conducted on hafnium metal [33-42].

To date, the behaviour of hafnium as surface coating in biological environments has not been studied. Little is known about osseointegration of hafnium-coated titanium implants. Thus, further studies of hafnium coating under biological conditions are required in order to determine the suitability of this material, as a surface coating for biomedical applications.

This study is aimed at evaluating osseointegration of hafnium-coated titanium as compared to uncoated titanium implants. This study has two main purposes. One is to find the osseointegration ability of hafnium metal, and the second purpose is to study the mechanism of which promotes better bone integration.

\section{Materials and Methods}

The experimental study was conducted in accordance with the approval from the "Institutional Animal Ethical Committee," approval no. BRULAC/SDCH/SIMATS/IAEC/09$2018 / 015$. The study was conducted on 16 Wistar Albino rats of both sexes, at the age of 6-7 months, weighing $2526.5 \pm 74.4 \mathrm{~g}$. Commercially pure self-tapping titanium osteosynthesis screws with a length of $4 \mathrm{~mm}$ and outer head diameter of $2 \mathrm{~mm}$ and thread diameter of $1.2 \mathrm{~mm}$ (LeForte System Bone Screw, Jeil Medical Corporation, Seoul $\left.{ }^{\circledR}\right)$ were used for this experiment.
Two groups were utilized in these studies:

(a) Commercially pure titanium implant (control group)

(b) Commercially pure titanium implant coated with hafnium metal (test group)

2.1. Coating Procedure. Commercially pure self-tapping micro titanium osteosynthesis implant screws $4 \mathrm{~mm}$ long were used with $2 \mathrm{~mm}$ head and $1.2 \mathrm{~mm}$ outer thread diameter, respectively (LeForte System Bone Screw, Jeil Medical Corporation, Seoul ${ }^{\circledR}$ ) (Figure 1).

The implant screws were coated with hafnium metal of $600 \mathrm{~nm}$ thickness using a magnetron stirrer. They were prepared by dipping the titanium screws in hafnium metal solution commercially available for industrial purposes and kept in a magnetic stirrer at $1000 \mathrm{rpm}$ followed by heat exposure in a hot air oven at 70-degree Celsius for 4 days, 6 hours daily. The uncoated (Figure 2) and coated (Figure 3) implants were observed under a light microscope at 100x magnification, and the procedure was carried out till an even coating thickness was obtained.

2.2. Surgical Procedure. Surgical procedures were performed under sterile conditions in a sterile animal laboratory surgical room. Rats were anesthetized with ketamine hydrochloride intraperitoneally and xylazine intramuscularly at the dosage of $70 \mathrm{mg} / \mathrm{kg}$ body weight and $10 \mathrm{mg} / \mathrm{kg}$ body weight, respectively. The ventral part of the neck was shaved and aseptically prepared with a solution of Betadine. A $2 \mathrm{~cm}$ length single median vertical skin incision was made on the anterior part of the neck, exposing the fascia and muscles underneath (Figure 4).

These tissues were retracted, and the mandibular bone was exposed. A standardized, round, through-and-through osseous defect of $3 \mathrm{~mm}$ in diameter was created with 


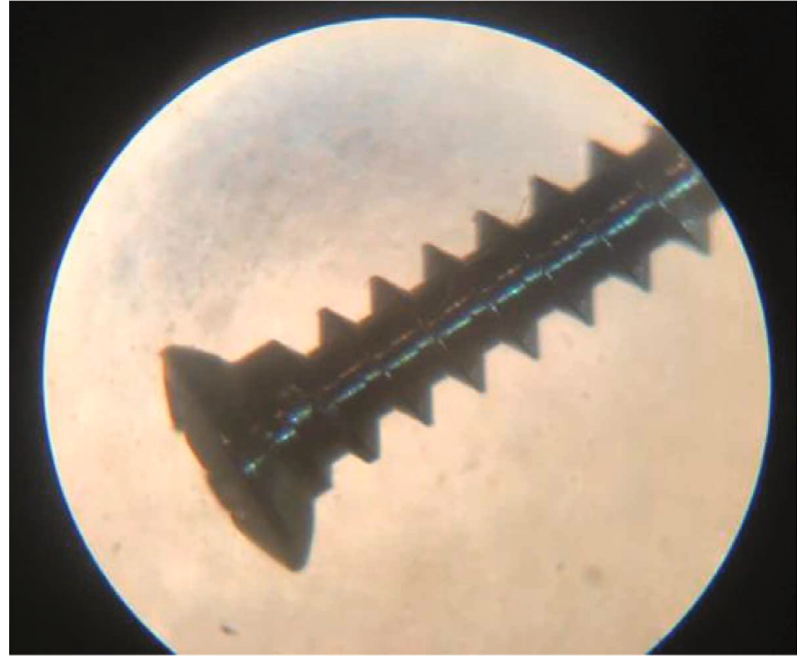

FIgURe 2: Photograph showing uncoated titanium screws under light microscope at 100x magnification.

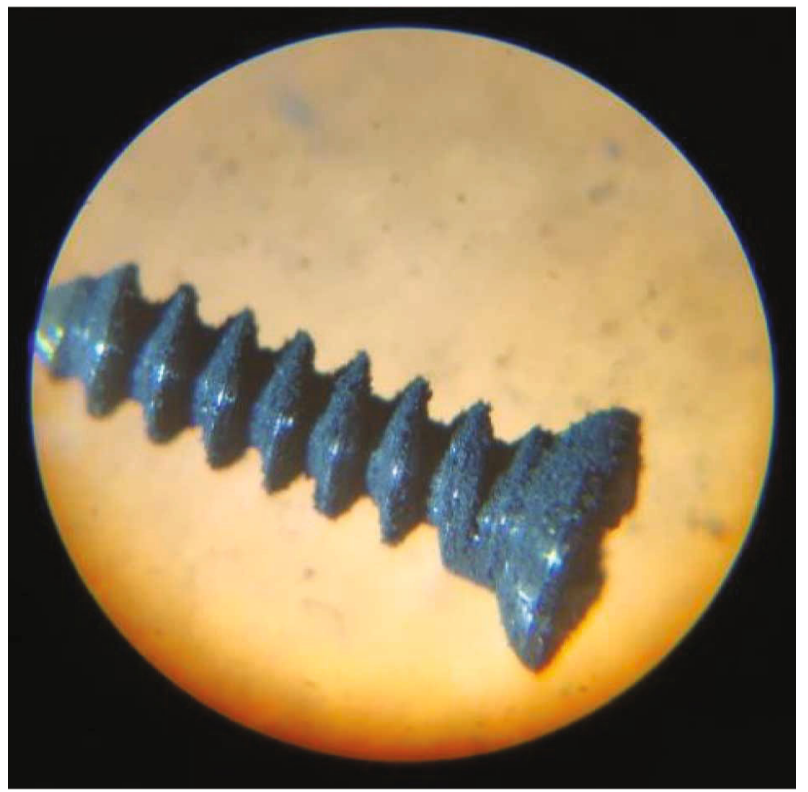

FIGURE 3: Photograph showing the hafnium-coated titanium implant screws under light microscope at 100x magnification.

simultaneous driving of implant inside, similarly on the single side of the jaw, with a self-tapping screw mounted on a straight hand-piece driller controlled by the motor regulator. During the drilling process, the tissues were periodically irrigated with saline water. Care was taken during the surgery not to damage the vessels. Titanium screws were then implanted in the drilled site, in such a way that the implant should penetrate the bone slowly by the clockwise selftapping procedure.

The implanted screws' stability was checked and noted with a torque apparatus during insertion of implant. The torque apparatus consisted of a torque wrench and an implant hex drive; the head of which was specially customised according to the head of the implant screw (Figure 5).

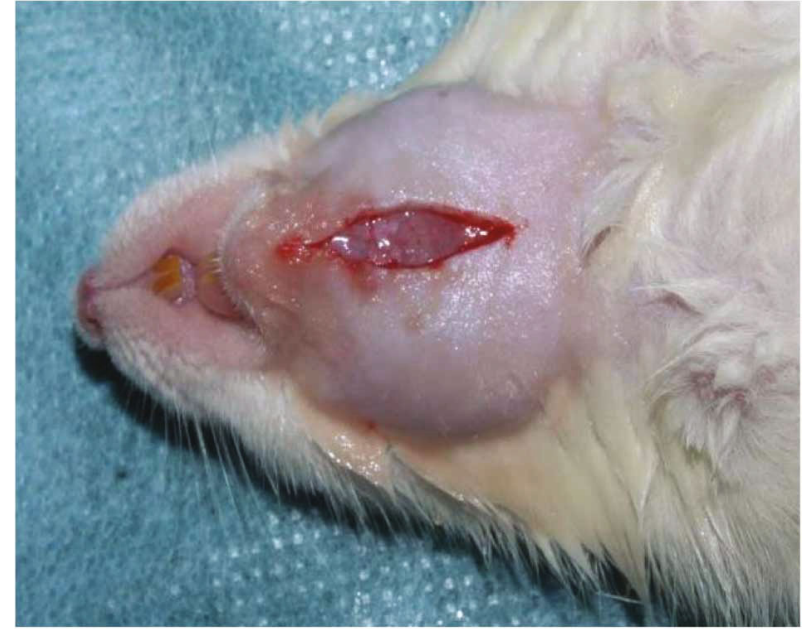

FIgURE 4: Photograph showing a $2 \mathrm{~cm}$ length single median vertical skin incision was made on the anterior part of the neck.

The same procedure was carried in both the groups. Both the titanium and hafnium-coated screws were implanted in respective groups (Figure 6).

Then, the tissue flaps were sutured with resorbable suture threads (Vicryl 5/0, Ethicon ${ }^{\circledR}$, Somerville, NJ, USA) and Betadine ointment was applied upon the sutured area, and then, the rats were isolated in separate cages.

2.3. Postoperative Care for the Animal. Analgesics like Fevastin $10 \mathrm{mg} / \mathrm{kg}$ body weight (intramuscularly) and diclofenac $10 \mathrm{mg} / \mathrm{kg}$ body weight (orally) were administered. The rats were examined daily for any change in body weight or signs of inflammation or infection in the surgical site.

Tissue samples were collected at the end of 4 weeks and 8 weeks by euthanizing the animals in a $\mathrm{CO}_{2}$ chamber, and the mandibular bone alone containing the implant was dissected, photographed, and processed for histopathological examination. The excess fascial and muscular tissues adherents to the bones were removed. The mandibular bony part with the implant was fixed in 10\% neutral buffered formalin. The removal torque was measured and noted in the same manner as mentioned earlier for stability using the torque apparatus, while the tissue samples were collected.

2.4. Histological Preparation. The fixed tissues were taken out and later decalcified in $20 \%$ formic acid for 7 days. Afterwards, the samples were embedded in paraffin and serial sections were cut at a thickness of $5 \mu \mathrm{m}$. The sections were then processed for hematoxylin and eosin staining and mounted permanently in DPX. For bone and connective tissue examination, the Masson's trichrome staining was done. The stained samples were photographed and analysed for histopathology.

\section{Results}

3.1. Primary Stability (Insertion Torque) and Removal Torque. The primary stability measured using removal torque was measured for both groups studied. The mean 


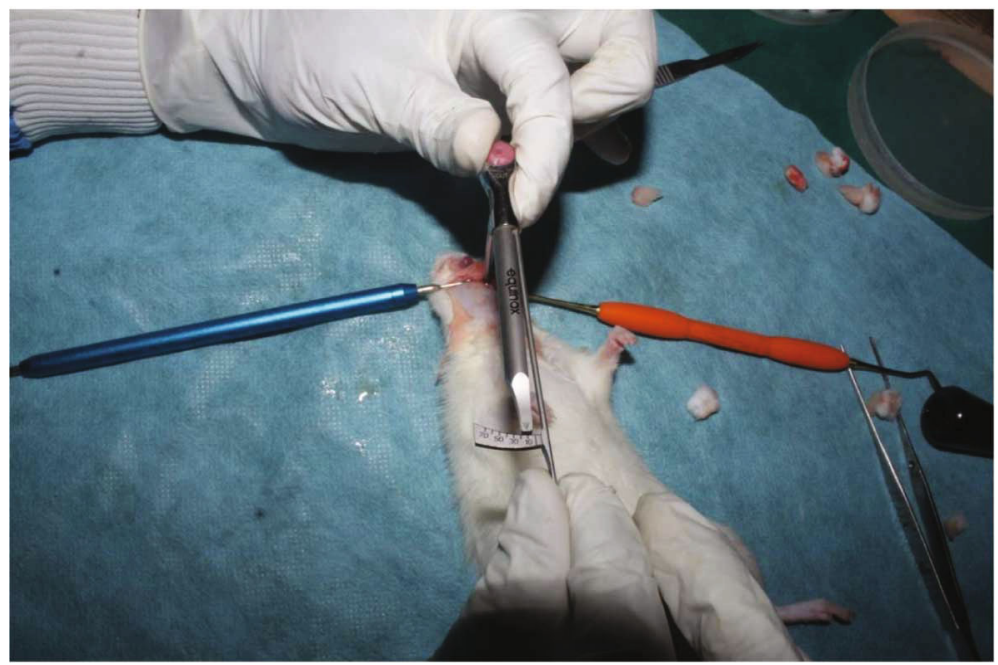

Figure 5: Photograph showing torque wrench (range 0-70 N) and an implant hex drive with head specially customised according to the head of the implant screw.

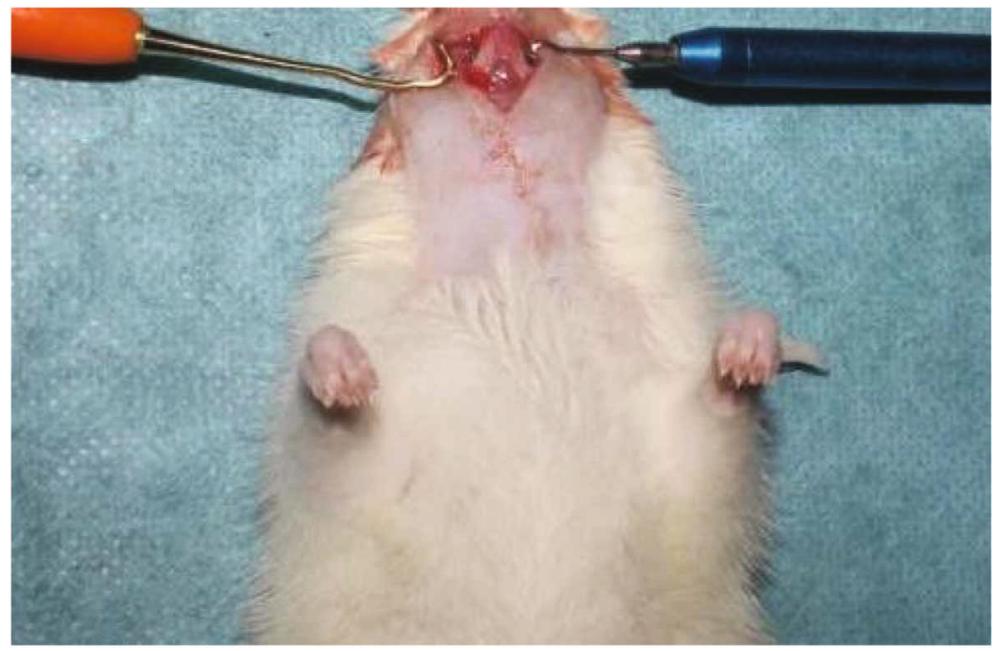

FIGURE 6: Photograph showing titanium and hafnium-coated screws implanted in respective sites.

TABLE 1: Table showing values (mean $\pm \mathrm{SD}$ ) of independent $t$-test for insertion torque (primary stability) and removal torque for both the groups $(p<0.05)$.

\begin{tabular}{lccc}
\hline Torque values & $\begin{array}{c}\text { Group A (pure titanium screws) } \\
n=12\end{array}$ & $\begin{array}{c}\text { Group B (hafnium-coated screws) } \\
n=12\end{array}$ & $\begin{array}{c}\text { Significance } \\
\left({ }^{*} p \text { value }\right)\end{array}$ \\
\hline Insertion torque or primary stability $\left(\mathrm{N} / \mathrm{cm}^{2}\right)$ & $22.08 \pm 2.57$ & $25.42 \pm 3.96$ & $p<0.05(0.003)$ \\
Removal torque $\left(\mathrm{N} / \mathrm{cm}^{2}\right)$ & $25.42 \pm 2.57$ & $29.17 \pm 2.88$ & $p<0.05(0.023)$ \\
\hline
\end{tabular}

${ }^{*}$ Independent sample $t$-test.

insertion torque/primary stability in the control group (pure titanium screws) was $22.08 \pm .57 \mathrm{~N} / \mathrm{cm}^{2}$ and that in the test group (hafnium-coated screws) was $25.42 \pm 3.96 \mathrm{~N} / \mathrm{cm}^{2}$. The mean removal torque of the control group was 25.42 $\pm 2.57 \mathrm{~N} / \mathrm{cm}^{2}$ and that of the test group was $29.17 \pm 2.88 \mathrm{~N}$ $/ \mathrm{cm}^{2}$. The results were statistically significant $(p<0.05)$ when the independent Student $t$-test was performed (IBM
SPSS Statistics 20) (Table 1). The corresponding bar graph for the primary stability and removal torque is depicted (Figures 7 and 8).

3.2. Histomorphometric Analysis. The histopathological evaluation was performed at 2 intervals, viz., 4 weeks (Figure 9) and 8 weeks (Figure 10), with two stains, namely, 


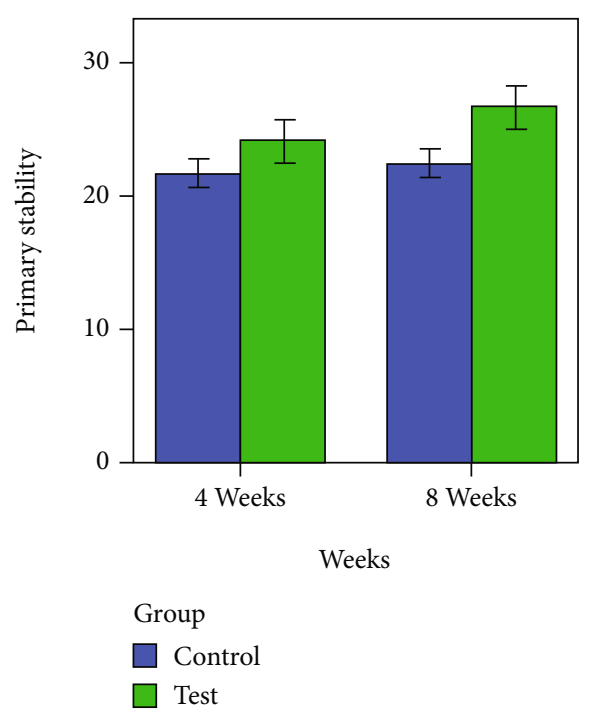

Figure 7: Bar graph shows mean primary stability torque values \pm 1 SE of titanium and hafnium-coated implant screws.

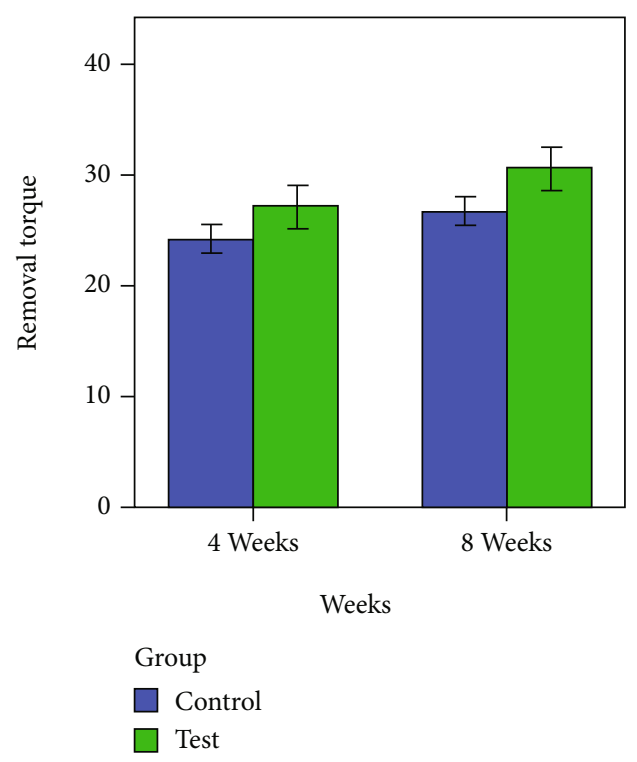

FIGURE 8: Bar graph shows mean removal torque values \pm 1 SE of titanium and hafnium-coated implant screws.

hematoxylin and eosin stain and Masson's trichrome stain under magnifications $4 \mathrm{x}, 20 \mathrm{x}, 40 \mathrm{x}$, and 40x, respectively.

At the end of 4 weeks, histopathological evaluation demonstrated the formation and accumulation of connective tissue fibres adjacent to the implant region in the control and test groups. The presence of collagen-rich connective tissue fibres in the test group indicates the course of transformation and maturation of the endochondral ossification. The screw threads were tightly lodged in the adjacent cortical bone tissues.

At the end of 8 weeks, histopathological evaluation demonstrated the accumulation of connective tissue fibres along with the presence of thin layers of newly transformed bone (asterisk marked) which are also in connection with trabec- ular bone in some regions. The difference between the control and test groups is the site of formation of newly formed bone. In the control group, it is formed mostly at the inner core region of the bone away from the boneimplant contact site $(*)$. But in the test group, the bone is formed at the implant contact site influencing the implant surfaces for better osseointegration $(*)$. The trabecular bone tissue formation at the bone-implant contact site depicts contact osteogenesis confirmed by Masson's trichrome stain $(40 \mathrm{x})$ visible as green-coloured structures.

3.3. Toxicology. The animals were sacrificed after 4 weeks and 8 weeks and sent for enzyme toxicity, viz., AST, ALT, and CK using an ELISA kit (Elabscience ${ }^{\circledR}$ ) with 96 wells and an Automatic ELISA Plate Analyser (Readwell Touch, ROBONIK $^{\circledR}$ ). The data for the enzyme toxicity is listed (Table 2). It was found that the results are statistically insignificant $(p>0.05)$ (independent Student's $t$-test, IBM Statistics 20).

3.4. Body Weight of Animal. The body weight of rats was measured before the surgery and after each week, and any signs of inflammation or infection were carefully monitored. The data for body weight of animals sacrificed after 8 weeks (Table 3) have been listed. The body weight of the rats studied for 4 weeks decreased from before surgery till the end of the 2nd week, after which there was an increase in the body weight. The body weight of the rats studied for 8 weeks decreased from before surgery till the end of the $4^{\text {th }}$ week, after which there was an increase in the body weight.

\section{Discussion}

In the current study, hafnium coating appears to have offered similar biocompatibility (aspartate transaminase (AST), alanine aminotransferase (ALT), and creatine kinase (CK) enzyme assay), statistically significant improvement (independent Student's $t$-test, $p<0.05)$ in insertion torque $(25.42 \pm 3.96)$ and removal torque $(29.17 \pm 2.88)$ than commercially pure titanium with insertion torque $(22.08 \pm .57)$ and removal torque $(25.42 \pm 2.57)$. Hafnium has proved to have good tissue response and osseointegration, along with required mechanical properties [39-48]. Though these results seem to favour hafnium, it is necessary to analyse the factors that could have confounded our study.

Animal studies must have a proper protocol to be followed for care of animals used in the study as laid down by the Institutional Animal Ethical Committee (IAEC). The health of the animal was monitored throughout the study. The body weight of the animal was recorded at the start of the surgery and at the end of each week (Table 3). Signs of infection or inflammation were also checked. Proper and timely feeding of the animal was carried out every day to ensure good health of the animal. The results showed that there is an increase in the body weight towards the end of 4 weeks as well as 8 weeks, suggestive of a positive growth phase (Figures 5 and 6). Since it was a split mouth study, the health of the animal could not have affected the outcome or caused variation between the test and control groups. 


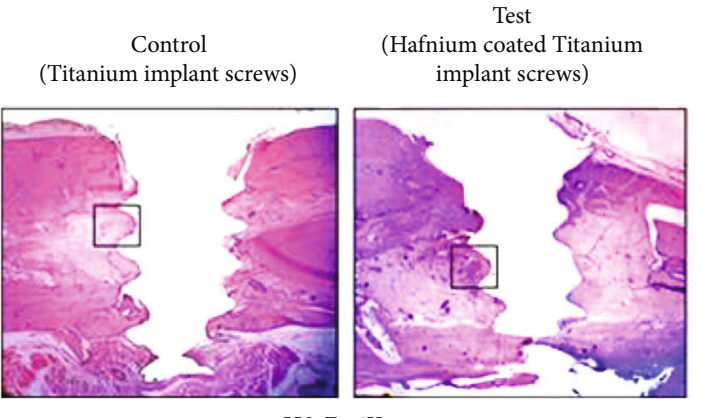

$\mathrm{H} \& \mathrm{E}: 4 \mathrm{X}$

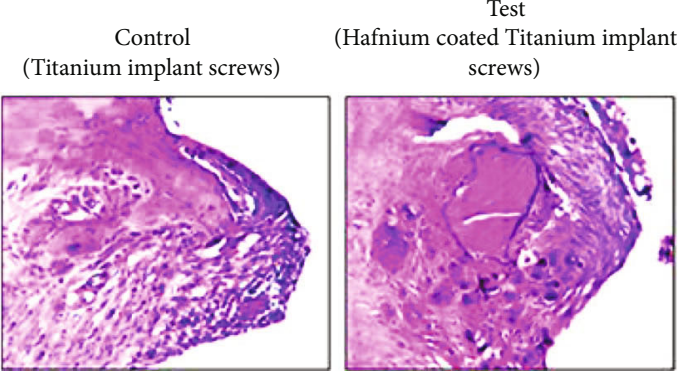

H\& E : 40X

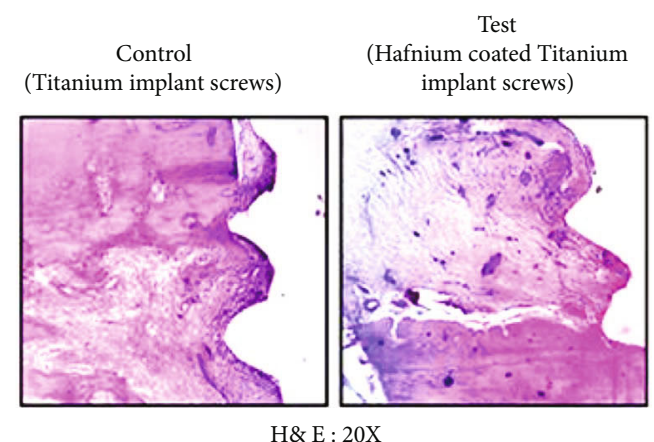

H\& E : 20X

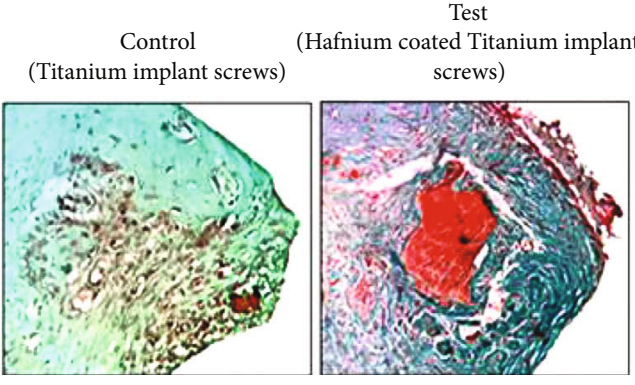

MTC : 40X

FIGURE 9: Photomicrographs showing the histopathology of the control (titanium implant screws) and the test group (hafnium-coated titanium implant screws) in 4 weeks.

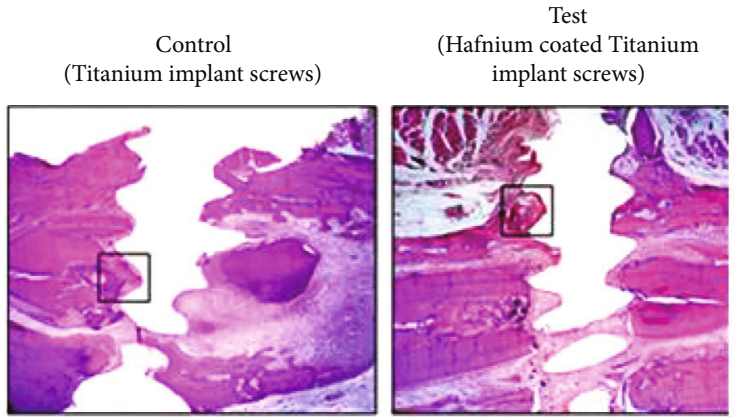

$\mathrm{H} \& \mathrm{E}: 4 \mathrm{X}$

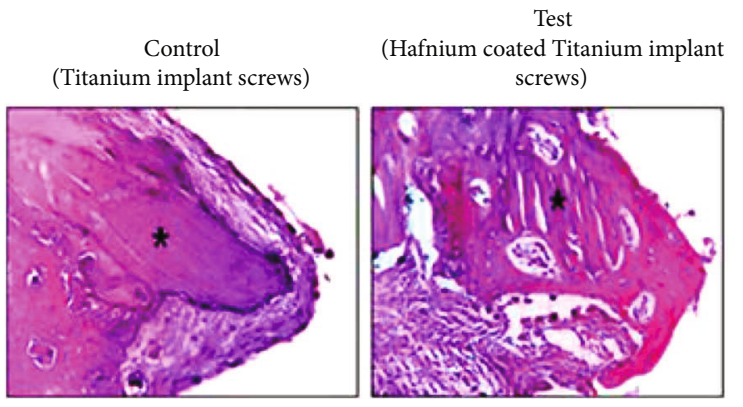

H\& E : 40X

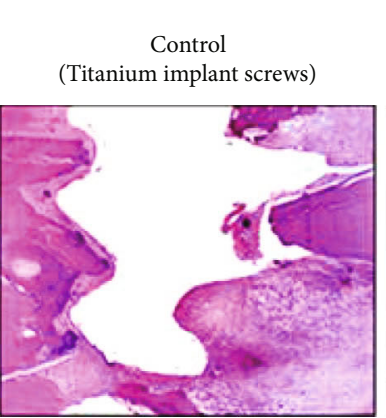

(Hafnium coated Titanium implant screws)

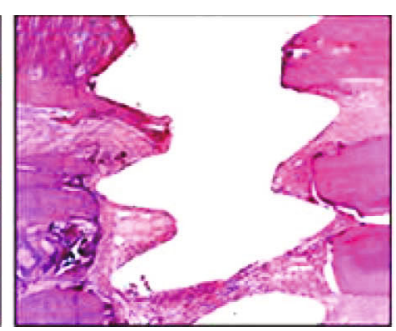

$\mathrm{H} \& \mathrm{E}: 20 \mathrm{X}$

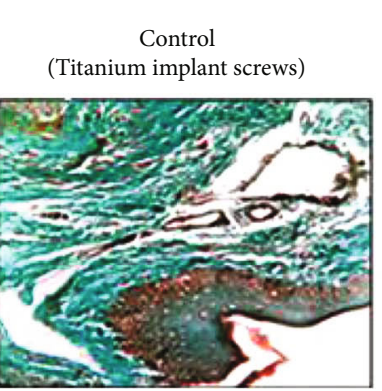

Test
(Hafnium coated Titanium implant screws)

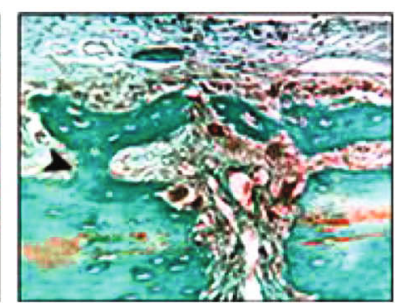

MTC : 40X

FIgURE 10: Photomicrographs showing the histopathology of the control (titanium implant screws) and the test group (hafnium-coated titanium implant screws) in 8 weeks.

The dexterity of the operator could be a confounding variable in the current study. However, the implant screws selected were a self-threading type with drill driver provided by the manufacturer of the implant screws. Hence, primary stability could not have been affected by the dexterity of the implant placement [49-52].

The implant screws of both groups were placed in the mandible of the animal. As both groups were in the same 
TABLE 2: Table showing data for enzyme toxicity (AST, ALT, and CK) for both the groups $(p<0.05)$.

\begin{tabular}{lccc}
\hline Enzyme toxicity & Group A (pure titanium screws) & Group B (hafnium-coated screws) & Significance $\left({ }^{*} p\right.$ value) \\
\hline AST & $n=12$ & $79.94 \pm 1.78$ & $p>0.05(\mathrm{NS})$ \\
ALT & $80.43 \pm 1.35$ & $49.27 \pm 3.52$ & $p>0.05(\mathrm{NS})$ \\
CK & $47.85 \pm 2.75$ & $0.78 \pm 0.08$ & $p>0.05(\mathrm{NS})$ \\
\hline
\end{tabular}

${ }^{*}$ Independent sample $t$-test; NS: not significant.

TABLE 3: Table showing data for body weight of rats before surgery till the 8th week after surgery for both the groups.

\begin{tabular}{lccr}
\hline \multirow{2}{*}{ Body weight } & Group A (pure titanium screws) & Group B (hafnium-coated screws) & $n=12$ \\
\hline Before surgery & $232.66 \pm 4.84$ & $232.66 \pm 4.84$ & Significance $\left({ }^{*} p\right.$ value) \\
After surgery & $230.83 \pm 13.54$ & $230.83 \pm 13.54$ & $p>0.05(0.515)$ \\
\hline
\end{tabular}

${ }^{*}$ Independent sample $t$-test.

anatomic location in the animal, this parameter could not have affected the outcome of the results. Similar studies conducted in animals also mention east variations in density of bone in the anatomically same region [53]. Magnetic stirring method was used for coating the implant screws with hafnium which ensures the same thickness of coating for all samples. Previous studies have shown the use of similar coating methods [54, 55], although the coating thickness or delamination of coating was not tested for in this study.

The accuracy of histopathology may be affected by the handling and processing of tissue samples [56, 57]. However, in this study, histopathology was carried out by an experienced senior pathologist, expert in animal tissue handling for over 15 years. Utmost care was taken to maintain consistent protocol. Effects of this would not have affected one group selectively. The limitations of the current study include the inability to measure the thickness of the coating prior to placement of the implant screws. Another limitation of this study is that the delamination of coating was not tested before the implant screws were placed in the animal model.

Future scope of the study involves studies on delamination of the coating, the scratch resistance of the coating in intraoral scenario, biofilm formation on the surface of the coating, and the side effects of leaching of the metal in the body. Researchers have emphasized that hafnium is a potential surface coating solution for titanium implants that can improve osseointegration. If research could be expanded to include hafnium as a metal for coating over dental implants or as a dental implant material to improve osseointegration, it could be used to investigate the potential of this metal in the rehabilitation of both intra- and extraoral defects, as well as in medically vulnerable patients with compromised bone quality [58]. Research could also be expanded on the possibility of newer metal alloys with hafnium for use as dental implants. Meticulous and extensive phase III and phase IV multicentre randomized control trials are required for breakthrough in this implant biomaterial.

\section{Conclusion}

Hafnium coating of endosseous implants in the current study on rat mandibles showed equivalent osseointegration and faster healing when compared to the gold standard, titanium. Hafnium is also similar to titanium in its biocompatibility with osseous tissues. Further human trials of hafniumcoated implants are needed to understand the biological behaviour better to enhance clinical performance.

\section{Data Availability}

The authors confirm that the data supporting the findings of this study are available within the article.

\section{Conflicts of Interest}

The authors declare no conflicts of interest.

\section{Authors' Contributions}

This work was carried out in collaboration among all authors. Author 1 designed the study, performed the research and the statistical analysis, wrote the protocol, and wrote the first draft of the manuscript. Authors 2, 3, and 4 managed the analyses and revision of the study. Authors 5 and 6 managed the literature searches and manuscript revision. All authors read and approved the final manuscript.

\section{Acknowledgments}

The team extends our sincere gratitude to the Saveetha Dental College and Hospitals for their constant support and successful completion of this work.

\section{References}

[1] B. A. Fishero, N. Kohli, A. Das, J. J. Christophel, and Q. Cui, "Current concepts of bone tissue engineering for craniofacial bone defect repair," Craniomaxillofacial Trauma \& Reconstruction, vol. 8, no. 1, pp. 23-30, 2015. 
[2] M. A. K. Liebschner, "Biomechanical considerations of animal models used in tissue engineering of bone," Biomaterials, vol. 25, no. 9, pp. 1697-1714, 2004.

[3] Y. Zhang, L. Hu, M. Lin, S. Cao, Y. Feng, and S. Sun, "RhBMP2-loaded PLGA/titanium nanotube delivery system synergistically enhances osseointegration," ACS Omega, vol. 6, no. 25, pp. 16364-16372, 2021.

[4] M. F. Kunrath, R. P. Dos Santos, S. D. de Oliveira, R. Hubler, P. Sesterheim, and E. R. Teixeira, "Osteoblastic cell behavior and early bacterial adhesion on macro-, micro-, and nanostructured titanium surfaces for biomedical implant applications," The International Journal of Oral \& Maxillofacial Implants, vol. 35, no. 4, pp. 773-781, 2020.

[5] B. Möller, H. Terheyden, Y. Açil et al., "A comparison of biocompatibility and osseointegration of ceramic and titanium implants: an _in vivo_ and _in vitro_study," International Journal of Oral and Maxillofacial Surgery, vol. 41, no. 5, pp. 638-645, 2012.

[6] A. M. Ektessabi, J. Mouhyi, P. Louvette, and L. Sennerby, "Investigation of corrosion and ion release from titanium dental implant," International Journal of PIXE, vol. 7, no. 3n04, pp. 179-199, 1997.

[7] R. S. Bedi, D. E. Beving, L. P. Zanello, and Y. Yan, "Biocompatibility of corrosion-resistant zeolite coatings for titanium alloy biomedical implants," Acta Biomaterialia, vol. 5, no. 8, pp. 3265-3271, 2009.

[8] R. Shah, R. Thomas, T. M. Gowda, T. K. A. Baron, G. G. Vemanaradhya, and S. Bhagat, "In vitro evaluation of osteoblast response to the effect of injectable platelet-rich fibrin coating on titanium disks," The Journal of Contemporary Dental Practice, vol. 22, no. 2, pp. 107-110, 2021.

[9] Z. Badran, X. Struillou, N. Strube et al., "Clinical performance of narrow-diameter titanium-zirconium implants: a systematic review," Implant Dentistry, vol. 26, no. 2, pp. 316-323, 2017.

[10] J. Li, J. A. Jansen, X. F. Walboomers, and J. J. van den Beucken, "Mechanical aspects of dental implants and osseointegration: a narrative review," Journal of the Mechanical Behavior of Biomedical Materials, vol. 103, article 103574, 2020.

[11] A. Robau-Porrua, Y. Pérez-Rodríguez, L. M. Soris-Rodríguez, O. Pérez-Acosta, and J. E. González, "The effect of diameter, length and elastic modulus of a dental implant on stress and strain levels in peri-implant bone: a 3D finite element analysis," Bio-medical Materials and Engineering, vol. 30, no. 5-6, pp. 541-558, 2020.

[12] A. Brizuela, M. Herrero-Climent, E. Rios-Carrasco et al., "Influence of the elastic modulus on the osseointegration of dental implants," Materials, vol. 12, no. 6, p. 980, 2019.

[13] R. N. Salaie, A. Besinis, H. Le, C. Tredwin, and R. D. Handy, "The biocompatibility of silver and nanohydroxyapatite coatings on titanium dental implants with human primary osteoblast cells," Materials Science \& Engineering. C, Materials for Biological Applications, vol. 107, article 110210, 2020.

[14] J. Knaus, D. Schaffarczyk, and H. Cölfen, "On the future design of bio-inspired polyetheretherketone dental implants," Macromolecular Bioscience, vol. 20, no. 1, article e1900239, 2020.

[15] T. P. Chaturvedi, "An overview of the corrosion aspect of dental implants (titanium and its alloys)," Indian Journal of Dental Research, vol. 20, no. 1, pp. 91-98, 2009.

[16] N. Adya, M. Alam, T. Ravindranath, A. Mubeen, and B. Saluja, "Corrosion in titanium dental implants: literature review," The
Journal of Indian Prosthodontic Society, vol. 5, no. 3, p. 126, 2005.

[17] V. K. Balla, S. Bodhak, S. Bose, and A. Bandyopadhyay, "Porous tantalum structures for bone implants: fabrication, mechanical and in vitro biological properties," Acta Biomaterialia, vol. 6, no. 8, pp. 3349-3359, 2010.

[18] R. Cohen, "A porous tantalum trabecular metal: basic science," The American Journal of Orthopedics, vol. 31, no. 4, pp. 216217, 2002.

[19] Q. Wang, H. Zhang, H. Gan, H. Wang, Q. Li, and Z. Wang, "Application of combined porous tantalum scaffolds loaded with bone morphogenetic protein 7 to repair of osteochondral defect in rabbits," International Orthopaedics, vol. 42, no. 7, pp. 1437-1448, 2018.

[20] E. H. Mrosek, H.-W. Chung, J. S. Fitzsimmons, S. W. O’Driscoll, G. G. Reinholz, and J. C. Schagemann, "Porous tantalum biocomposites for osteochondral defect repair," Bone \& joint research, vol. 5, no. 9, pp. 403-411, 2016.

[21] Z. Tang, Y. Xie, F. Yang et al., "Porous tantalum coatings prepared by vacuum plasma spraying enhance bmscs osteogenic differentiation and bone regeneration in vitro and in vivo," PLoS One, vol. 8, no. 6, article e66263, 2013.

[22] M. Arciniegas, C. Aparicio, J. M. Manero, and F. J. Gil, "Low elastic modulus metals for joint prosthesis: tantalum and nickel-titanium foams," Journal of the European Ceramic Society, vol. 27, no. 11, pp. 3391-3398, 2007.

[23] T. Lu, J. Wen, S. Qian et al., "Enhanced osteointegration on tantalum-implanted polyetheretherketone surface with bone-like elastic modulus," Biomaterials, vol. 51, pp. 173183, 2015.

[24] R. Korabi, K. Shemtov-Yona, and D. Rittel, "On stress/strain shielding and the material stiffness paradigm for dental implants," Clinical Implant Dentistry and Related Research, vol. 19, no. 5, pp. 935-943, 2017.

[25] R. Saha, R. B. Inturi, and J. A. Barnard, "Effect of thickness and annealing on stress in tantalum and tantalum nitride thin film hard Coatings," MRS Online Proceedings Library, vol. 436, 1996.

[26] J. Rituerto Sin, A. Neville, and N. Emami, "Corrosion and tribocorrosion of hafnium in simulated body fluids," Journal of Biomedical Materials Research. Part B, Applied Biomaterials, vol. 102, no. 6, pp. 1157-1164, 2014.

[27] S. Mohammadi, M. Esposito, M. Cucu, L. E. Ericson, and P. Thomsen, "Tissue response to hafnium," Journal of Materials Science. Materials in Medicine, vol. 12, no. 7, pp. 603611, 2001.

[28] H. Matsuno, A. Yokoyama, F. Watari, M. Uo, and T. Kawasaki, "Biocompatibility and osteogenesis of refractory metal implants, titanium, hafnium, niobium, tantalum and rhenium," Biomaterials, vol. 22, no. 11, pp. 1253-1262, 2001.

[29] H. Lee, D.-H. Choe, S. Jo et al., "Unveiling the origin of robust ferroelectricity in Sub-2 nm hafnium zirconium oxide films," ACS Applied Materials \& Interfaces, vol. 13, no. 30, pp. 36499-36506, 2021.

[30] P. Ghana, S. Schrader, T. Rajeshkumar et al., "Reduced arene complexes of hafnium supported by a triamidoamine ligand," Angewandte Chemie, International Edition, vol. 60, no. 25, pp. 14179-14187, 2021.

[31] E. C. Constable, "Evolution and understanding of the d-block elements in the periodic table," Dalton Transactions, vol. 48, no. 26, pp. 9408-9421, 2019. 
[32] P. Parsons, "The periodic table: a visual guide to the elements," Teaching Science, vol. 60, 2014.

[33] K. Edalati, Z. Horita, and Y. Mine, "High-pressure torsion of hafnium," Materials Science and Engineering: A, vol. 527, no. 7, pp. 2136-2141, 2010.

[34] X.-W. Gu, J. Pei, K. Shao, H.-M. Wen, B. Li, and G. Qian, "Chemically stable hafnium-based metal-organic framework for highly efficient $\mathrm{C} 2 \mathrm{H} 6 / \mathrm{C} 2 \mathrm{H} 4$ separation under humid conditions," ACS Applied Materials \& Interfaces, vol. 13, no. 16, pp. 18792-18799, 2021.

[35] H. Sato, M. Kikuchi, M. Komatsu, O. Okuno, and T. Okabe, "Mechanical properties of cast Ti-Hf alloys," Journal of Biomedical Materials Research. Part B, Applied Biomaterials, vol. 72B, no. 2, pp. 362-367, 2005.

[36] M. A. Jenkins, K. E. K. Holden, S. W. Smith et al., "Determination of hafnium zirconium oxide interfacial band alignments using internal photoemission spectroscopy and X-ray photoelectron spectroscopy," ACS Applied Materials \& Interfaces, vol. 13, no. 12, pp. 14634-14643, 2021.

[37] S.-Y. Chun, "Low resistivity hafnium nitride thin films deposited by inductively coupled plasma assisted magnetron sputtering in microelectronics," Journal of Nanoscience and Nanotechnology, vol. 21, no. 7, pp. 4129-4132, 2021.

[38] Z. Hu, Y. Wang, and D. Zhao, "The chemistry and applications of hafnium and cerium(iv) metal-organic frameworks," Chemical Society Reviews, vol. 50, no. 7, pp. 4629-4683, 2021.

[39] B. R. Levine, S. Sporer, R. A. Poggie, C. J. Della Valle, and J. J. Jacobs, "Experimental and clinical performance of porous tantalum in orthopedic surgery," Biomaterials, vol. 27, no. 27, pp. 4671-4681, 2006.

[40] A. Yousef, I. Akhtyamov, F. Shakirova, L. Zubairova, E. Gatina, and C. I. C. Aliev, "Effect of hafnium and titanium coated implants on several blood biochemical markers after osteosynthesis in rabbits," International Journal of Clinical and Experimental Medicine, vol. 7, no. 10, pp. 3473-3477, 2014.

[41] J.-Y. Choi, S. Kim, S. B. Jo et al., "A laminin-211-derived bioactive peptide promotes the osseointegration of a sandblasted, large-grit, acid-etched titanium implant," Journal of Biomedical Materials Research. Part A, vol. 108, no. 5, pp. 12141222, 2020.

[42] X. Liu, D. Li, Y. Liang et al., "Establishment of anti-oxidation platform based on few-layer molybdenum disulfide nanosheet-coated titanium dioxide nanobelt nanocomposite," Journal of Colloid and Interface Science, vol. 601, pp. 167-176, 2021.

[43] A. Yousef, I. Akhtiamov, F. Shakirova, L. Zubairova, E. Gatina, and E. Aliev, "Changes of blood composition in rabbits before and after osteosynthesis utilizing coated and non-coated metal implants," International Journal of Biomedical and Healthcare Science, vol. 4, no. 1, pp. 21-27, 2014.

[44] T. L. McGinnity, V. Sokolova, O. Prymak, P. D. Nallathamby, M. Epple, and R. K. Roeder, "Colloidal stability, cytotoxicity, and cellular uptake of $\mathrm{HfO}_{2}$ nanoparticles," Journal of Biomedical Materials Research Part B: Applied Biomaterials, vol. 109, no. 10, pp. 1407-1417, 2021.

[45] C. Herranz-Diez, C. Mas-Moruno, S. Neubauer et al., "Tuning mesenchymal stem cell response onto titanium-niobium-hafnium alloy by recombinant fibronectin fragments," ACS Applied Materials \& Interfaces, vol. 8, no. 4, pp. 2517-2525, 2016.
[46] L. Gällentoft, L. M. E. Pettersson, N. Danielsen, J. Schouenborg, C. N. Prinz, and C. E. Linsmeier, "Size-dependent long-term tissue response to biostable nanowires in the brain," Biomaterials, vol. 42, pp. 172-183, 2015.

[47] S. Pereira, P. Veeraraghavan, S. Ghosh, and M. Gandhi, "Animal experimentation and ethics in India: the CPCSEA makes a difference," Alternatives to Laboratory Animals, vol. 32, 1 suppl, pp. 411-415, 2004.

[48] S. Farnaud, "The Dr Hadwen Trust for Humane Research: 39 years of replacement science," Alternatives to Laboratory Animals, vol. 37, Suppl 2, pp. 39-43, 2009.

[49] B. Wilmes and D. Drescher, "Impact of bone quality, implant type, and implantation site preparation on insertion torques of mini-implants used for orthodontic anchorage," International Journal of Oral and Maxillofacial Surgery, vol. 40, no. 7, pp. 697-703, 2011.

[50] A. Pozzi, G. Tabanella, A. Guida et al., "A novel parallel-walled dental implant with a self-tapping apex, conical connection, and platform shifting: short-term results from a retrospective multicenter clinical study," The International Journal of Periodontics \& Restorative Dentistry, vol. 41, no. 4, pp. 521-529, 2021.

[51] A. Moroi, Y. Saito, A. Takayama, and K. Ueki, "Comparison of nonself-tapping tapered implant and self-tapping hybrid implant in terms of implant stability at initial and second fixation: a prospective randomized clinical trial," Clinical Implant Dentistry and Related Research, vol. 22, no. 6, pp. 679-688, 2020.

[52] G. Widmark, B. Friberg, B. Johansson, S. Sindet-Pedersen, and Å. Taylor, "Mk III: a third generation of the self-tapping Brånemark System ${ }^{\circledR}$ implant, including the new Stargrip internal grip design. A 1-year prospective four-center study," Clinical Implant Dentistry and Related Research, vol. 5, no. 4, pp. 273-279, 2003.

[53] A. I. Pearce, R. G. Richards, S. Milz, E. Schneider, and S. G. Pearce, "Animal models for implant biomaterial research in bone: a review," European Cells \& Materials, vol. 13, pp. 110, 2007.

[54] W. Fu, H. Yang, M. Li, M. Li, N. Yang, and G. Zou, “Anatase $\mathrm{TiO}_{2}$ nanolayer coating on cobalt ferrite nanoparticles for magnetic photocatalyst," Materials Letters, vol. 59, no. 27, pp. 3530-3534, 2005.

[55] D. Djozan, B. Ebrahimi, M. Mahkam, and M. A. Farajzadeh, "Evaluation of a new method for chemical coating of aluminum wire with molecularly imprinted polymer layer. Application for the fabrication of triazines selective solid-phase microextraction fiber," Analytica Chimica Acta, vol. 674, no. 1 , pp. 40-48, 2010.

[56] J. W. Crissman, D. G. Goodman, P. K. Hildebrandt et al., "Best practices guideline: toxicologic histopathology," Toxicologic Pathology, vol. 32, no. 1, pp. 126-131, 2004.

[57] L. Tomlinson, L. I. Boone, L. Ramaiah et al., "Best practices for veterinary toxicologic clinical pathology, with emphasis on the pharmaceutical and biotechnology industries," Veterinary Clinical Pathology, vol. 42, no. 3, pp. 252-269, 2013.

[58] V. Rajaraman, D. Nallaswamy, D. M. Ganapathy, and S. Kachhara, "Osseointegration of hafnium when compared to titanium-a structured review," The Open Dentistry Journal, vol. 15, no. 1, pp. 137-144, 2021. 